PACS: $61.43 . \mathrm{Gt}, 61.82 . \mathrm{Rx}, 61.82 . \mathrm{Bg}, 62.25 .+\mathrm{g}, 62.20 . \mathrm{Fe}, 62.40 .+\mathrm{i}, 62.60 .+\mathrm{v}, 62.80 .+\mathrm{f}$

\title{
ENERGY ACTIVATION SPECTRUM OF LOW-TEMPERATURE ACOUSTIC RELAXATION IN HIGH-PURITY IRON SINGLE CRYSTAL. SOLUTION OF THE INVERSE PROBLEM OF MECHANICAL SPECTROSCOPY BY THE TIKHONOV REGULARIZATION METHOD
}

\author{
(D) Yuri A. Semerenko \\ B. Verkin Institute for Low Temperature Physics and Engineering, National Academy of Sciences of the Ukraine \\ 47 Nauky Ave., 61103, Kharkiv, Ukraine \\ E-mail: semerenko@ilt.kharkov.ua \\ Received February 2, 2021; revised April 20, 2021; accepted April 22, 2021
}

When studying the temperature dependences of the acoustic absorption and the modulus of elasticity, absorption peaks are often observed, which correspond to the characteristic step on the temperature dependence of the modulus of elasticity. Such features are called relaxation resonances. It is believed that the occurrence of such relaxation resonances is due to the presence in the structure of the material of elementary microscopic relaxors that interact with the studied vibrational mode of mechanical vibrations of the sample. In a sufficiently perfect material, such a process is characterized by a relaxation time $\tau$, and in a real defective material by a relaxation time spectrum $P(\tau)$. Most often such relaxation processes have a thermally activated character and the relaxation time $\tau(T)$ is determined by the Arrhenius ratio $\tau(T)=\tau_{0} \exp \left(U_{0} / k T\right)$, and the characteristics of the process will be $U_{0}$ - activation energy, $\tau_{0}$ - period of attempts, $\Delta_{0}$ - characteristic elementary contribution of a single relaxator to the dynamic response of the material and their spectra. In the low temperatures region the statistical distribution of parameters $\tau_{0}$ and $\Delta_{0}$ can be neglected with exponential accuracy, and the relaxation contribution to the temperature dependences of absorption and the dynamic elasticity modulus of the material will be determined only by the activation energy spectrum $P(U)$ of microscopic relaxors. The main task of mechanical spectroscopy in the analysis of such relaxation resonances is to determine $U_{0}, \tau_{0}, \Delta_{0}$ and $P(U)$. It is shown, that the problem of recovering of spectral function $P(U)$ of acoustic relaxation of a real crystal can be reduced to the solving of the Fredholm integral equation of the first kind with an approximately known right part and concerns to a class of ill-posed problems. The method based on Tikhonov regularizing algorithm for recovering $P(U)$ from experimental temperature dependences of absorption or elasticity module is offered. It is established, that acoustic relaxation in high-purity iron single crystal in the temperature range $5-100 \mathrm{~K}$ is characterized by two-modes spectral function $P(U)$ with maxima at $0.037 \mathrm{eV}$ and $0.015 \mathrm{eV}$, which correspond to the $\alpha$-peak and its $\alpha^{\prime}$ satellite.

KEYWORDS: acoustic relaxation, Tikhonov regularization method, energy activation spectrum, acoustic absorption, modulus of elasticity

It was found [1] that the resonant frequency of forced resonant mechanical vibrations of solids is determined by both the geometric characteristics of the sample and its modulus of elasticity $M$. The amplitude of such resonant oscillations is proportional to the dissipation of the oscillation energy, which is characterized by the logarithmic decrement of oscillations $\delta$. This fact underlies the method of resonant mechanical spectroscopy, which allows you to study the elastic and dissipative properties of various materials. As a rule, the temperature dependences of absorption and elastic modulus are studied. In this case, peaks are often observed on the temperature dependence of absorption, which correspond to a characteristic step on the temperature dependence of the elastic modulus. Such an absorption peak, together with the corresponding step on the temperature dependence of the elastic modulus, is commonly called relaxation resonance. In the microscopic interpretation of such relaxation resonances, it is generally accepted [1] that their appearance is associated with the presence in the bulk of the material of thermally activated elementary microscopic relaxators (for example, a pair of kinks on a dislocation line) interacting with the studied vibrational mode of mechanical vibrations of the sample. The thermal activation of an individual relaxator is characterized by the relaxation time $\tau(T)$, and its dependence on temperature $T$ is described by the exponential Arrhenius expressiona:

$$
\tau(T)=\tau_{0} \exp \left(\frac{U_{0}}{k T}\right),
$$

where $k$ is the Boltzmann constant, $U_{0}$ is the activation energy, $\tau_{0}$ is the period of attempts.

If the mechanical vibrations of the sample excite a system of relaxators with the same values of the parameters $U_{0}$ and $\tau_{0}$, then in the resonance region in the approximation of a linear response, the temperature dependences of the 
elastic and dissipative characteristics of the material have the form of a Debye peak for the vibration decrement $\delta(T, \omega)$ and a "step" for the modulus defect $\Delta M(T, \omega) / M_{0}$ :

$$
\delta(T, \omega)=2 C_{r} \Delta_{0} \frac{\omega \tau}{1+\omega^{2} \tau^{2}} ; \quad \frac{\Delta M(T, \omega)}{M_{0}}=\frac{2 C_{r} \Delta_{0}}{\pi} \frac{1}{1+\omega^{2} \tau^{2}}
$$

In a sufficiently perfect material, such a process can be associated with three parameters, the values of which are determined by the energy and geometric parameters of a defect-free crystal: $U_{0}, \tau_{0}$ and $\Delta_{0}\left(\Delta_{0}\right.$ is the characteristic elementary contribution of an individual relaxator to the dynamic response of the crystal; $C_{r}$ is the relative volume concentration of such relaxators interacting with the considered vibrational mode of the sample). And the main task of mechanical spectroscopy in the analysis of such relaxation resonances is reduced to the determination of these parameters.

In a real material, due to the presence of various defects and randomly distributed structural distortions they create, there is a statistical scatter of parameters $U_{0}, \tau_{0}$ and $\Delta_{0}$. It is known [2] that the decrement of vibrations $\bar{\delta}(T, \omega)$ and the defect of the elastic modulus $\Delta \bar{M}(T, \omega) / M_{0}$ of a real material with defects in the low-temperature region $k T \ll U_{0}$ are determined by the statistical averaging of Debye expressions (2) over the entire spectrum of activation energies $U$ of local structural rearrangements (relaxators), characterized by a statistical distribution function $P(U)$, with a statistical spread of parameters $\tau_{0}$ and $\Delta_{0}$ with an exponential accuracy is negligible:

$$
\begin{gathered}
\bar{\delta}(T, \omega)=2 C_{r} \Delta_{0} \int_{0}^{\infty} \frac{\omega \tau(T, U)}{1+\omega^{2} \tau^{2}(T, U)} P(U) d U, \\
\frac{\Delta \bar{M}(T, \omega)}{M_{0}}=\frac{2 C_{r} \Delta_{0}}{\pi} \int_{0}^{\infty} \frac{P(U)}{1+\omega^{2} \tau^{2}(T, U)} d U
\end{gathered}
$$

where $\tau(T, U)=\tau_{0} \exp \left(\frac{U}{k T}\right)$.

In [3], it was suggested that the energy spectrum of low-temperature acoustic relaxation in iron can be described by the quasi-Gaussian distribution function

$$
P^{G}(U)=\frac{U}{\sqrt{2 \pi} D U_{0}} \exp \left[-\frac{\left(U-U_{0}\right)^{2}}{2 D^{2}}\right],
$$

with two parameters - the seed value of the activation energy $U_{0}$ corresponding to relaxation in an ideal defect-free crystal and its dispersion $D^{2}$. Under this assumption, it was possible to achieve a good description of the experimental temperature spectra $\delta$ and $\Delta M / M_{0}$ in the region of the $\alpha$-peak $\left(U_{0}=0.037 \mathrm{eV}, \tau_{0}=2.4 \cdot 10^{-11} \mathrm{~s}\right)$, observed at a temperature of $\approx 54 \mathrm{~K}$ (vibration frequency $\approx 88 \mathrm{kHz}$ ), by theoretical dependences (3) (Fig. 1).

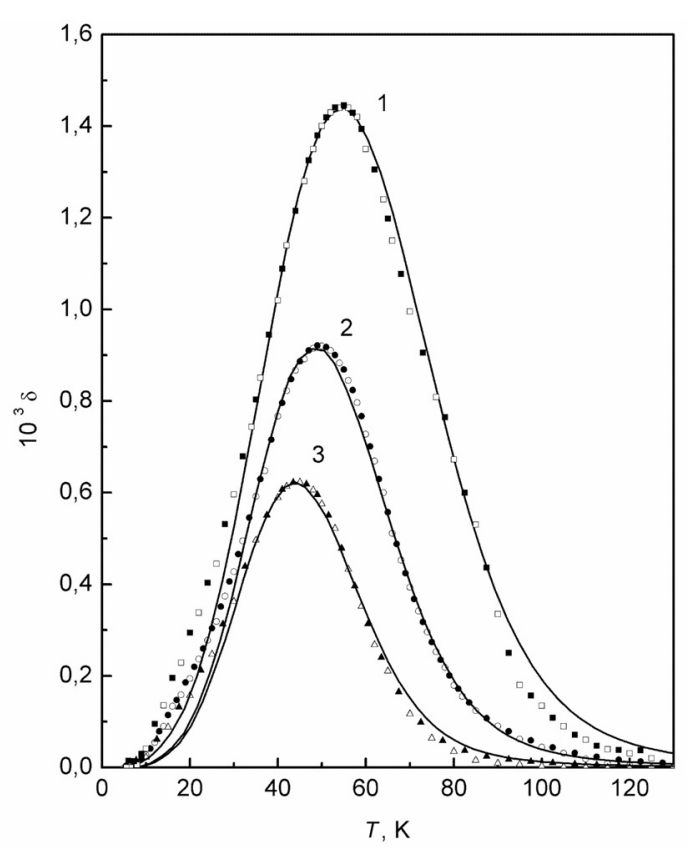

Figure 1. Temperature dependences of the vibration decrement in a single-crystal sample of high-purity iron with orientation $<731>$ in various structural states:

1 -specimen deformed at $T=300 \mathrm{~K}$ to a residual plastic deformation of $3 \%$, measurements were carried out immediately after deformation; 2 - the same sample, annealed at $T=300 \mathrm{~K}$ for 3 days; 3 - the same sample, annealed at $T=300 \mathrm{~K}$ for 11 years.

open symbols - experimental data [3]; shaded symbols - theoretical dependences calculated by formula (3) for the spectral function $P^{T}(U)$ that was found by the Tikhonov regularization method; solid lines - theoretical dependences calculated by formula (3) for the spectral function $P^{G}(U)$ (quasi-Gaussian distribution function of activation energy values given by expression (4) with an appropriate choice of values of distribution parameters). 
However, in the temperature range $\approx 15 \mathrm{~K}$, some discrepancy between the experimental and theoretical dependences was observed. A thorough analysis of a large amount of experimental data obtained by various authors, carried out in [4], showed that this discrepancy is probably associated with the presence of a weakly expressed $\alpha^{\prime}$-peak, which is more clearly manifested under other experimental conditions.

It seems advisable to solve the inverse problem - to restore $P(U)$ from experimental dependences $\delta, \Delta M / M_{0}$ and compare it with the "guessed" expression $P^{G}(U)$. This formulation of the problem belongs to the so-called inverse problems. The solution of inverse problems of mechanical spectroscopy has been repeatedly considered by various authors both from a theoretical and practical point of view [5], [6].

\section{RESTORATION OF THE ACTIVATION ENERGY SPECTRUM BY THE TIKHONOV REGULARIZATION METHOD}

Following the approach proposed in [7], we consider the problem of determining the energy spectrum of acoustic relaxation in a material with defects from the known temperature spectrum of the vibration decrement $\bar{\delta}(T, \omega)$ or defect of elastic modulus $\Delta \bar{M}(T, \omega) / M_{0}$.

Practically without limiting the generality of further consideration, one can replace in expressions (3) the infinite upper limit of integration by some value $U_{\max }$ corresponding to the upper limit of the spectrum, then the problem of finding the spectral function $P(U)$, from a known experimental spectrum $\bar{\delta}(T, \omega)$ or $\Delta \bar{M}(T, \omega) / M_{0}$ at a fixed frequency $\omega=$ const, is reduced to solving the Fredholm integral equation of the first kind with respect to $P(U)$ :

$$
\int_{U_{\min }}^{U_{\max }} K^{d, m}(T, U) P(U) d U=Z^{d, m}(T) \text { or in operator form } A p=z,
$$

where the kernel of the integral operator in the case of a decrement of vibrations and a defect of the modulus of elasticity, respectively, is

$$
K^{d}(T, U)=2 C_{r} \Delta_{0} \frac{\omega \tau_{0} \exp \left(\frac{U}{k T}\right)}{1+\omega^{2} \tau_{0}^{2} \exp \left(\frac{2 U}{k T}\right)} \text { and } K^{m}(T, U)=\frac{2 C_{r} \Delta_{0}}{\pi} \frac{1}{1+\omega^{2} \tau_{0}^{2} \exp \left(\frac{2 U}{k T}\right)},
$$

the experimental spectrum $Z^{d}(T)=\bar{\delta}(T)$ and $Z^{m}(T)=\frac{\Delta \bar{M}(T)}{M_{0}}$.

Let, for some right-hand side $\hat{Z}^{d, m}(T)$, the function $\hat{P}(U)$ be a solution to equation (5). However, since instead of the function $\hat{Z}^{d, m}(T)$ we know only its experimental approximation $Z^{d, m}(T)$, which differs little from $\hat{Z}^{d, m}(T)$, then we can only talk about finding an approximate to the $\hat{P}(U)$ "solution" $P(U)$ of equation (5). The solution to such a problem is associated with significant difficulties caused by the lack of stability of the solution to small changes in the right-hand side. This instability is connected with the fact that if instead of the exact right-hand side $\hat{Z}^{d, m}(T)$ of Eq. (5) we know only a certain approximation $Z^{d, m}(T)$ of it and a number $v>0$ characterizing the accuracy of the experimental data such that the deviation

$$
\rho_{Z}(\hat{Z}, Z) \leq v^{2},
$$

then, as possible approximate solutions, it is natural to take functions $P(U)$ for which

$$
\rho_{Z}(A p, Z) \leq v^{2},
$$

where

$$
\rho_{Z}\left(Z_{1}, Z_{2}\right)=\int_{T_{\min }}^{T_{\max }}\left\{Z_{1}(T)-Z_{2}(T)\right\}^{2} d T .
$$

However, there are infinitely many functions $P(U)$ satisfying this condition, and among them there are functions that differ as much as you like. Consequently, under these conditions, the problem of solving the integral equation (5) is underdetermined and unstable to small changes in the right-hand side. Therefore, it is impossible to take the exact solution of this equation (with an approximate right-hand side) as an approximate solution to equation (5). To find an 
approximate solution $P^{\alpha}(U)$ to equation (5) that satisfies the natural requirements that are embedded in the meaning of an approximate solution by the physical determinism of the phenomenon described by this equation and the possibility of physical interpretation of the solution, namely the conditions

$$
P^{\alpha}(U) \rightarrow \hat{P}(U) \text { at } v \rightarrow 0,
$$

it is necessary from the entire set of formal solutions $P(U)$ that satisfy condition (7) to select a function $P^{\alpha}(U)$ that satisfies condition (9). This can be done if there is additional information, at least of a qualitative nature, regarding the desired solution. We will assume that the desired spectrum $P^{\alpha}(U)$ does not have a fine structure, i.e. we can assume that the solution to the problem under consideration is a smooth function. As a measure of smoothness, consider the quantity

$$
\Omega[P]=\int_{U_{\min }}^{U_{\max }}\left\{\xi(U) \cdot P^{2}(U)+\chi(U) \cdot\left(\frac{d P(U)}{d U}\right)^{2}\right\} d U,
$$

where $\xi(U)$ and $\chi(U)$ are given non-negative continuous functions satisfying the condition $\xi^{2}(U)+\chi^{2}(U) \neq 0$ for any $U \in\left(U_{\min }, U_{\max }\right)$. This definition of smoothness is consistent with the visual representation of the smoothness of the graphs of functions.

Following [7], as the required spectrum $P^{\alpha}(U)$, we will choose from the family of approximate solutions $P(U)$ a function with the greatest smoothness (minimum fine structure). Mathematically, this problem is reduced to finding such a function $P^{\alpha}(U)$ that will achieve the minimum of the functional (10). The solution of such a problem for a conditional extremum is reduced to a problem for an unconditional extremum of a functional

$$
M_{\alpha}[P, Z]=\int_{T_{\min }}^{T_{\max }}\left\{\int_{U_{\min }}^{U_{\max }} K(T, U) P(U) d U-Z(T)\right\}^{2} d T+\alpha \Omega[P],
$$

where $\alpha>0$ is the regularization parameter, which can be determined by a given accuracy $v$ and, therefore, depends on $v$, i.e. $\alpha=\alpha(v)$. It can be shown [7] that $\alpha(v)$ is the function that convex downward, besides there is an estimate

$$
\alpha \leq \frac{v\|A\|^{2}}{\|z\|-v} .
$$

The solution to the minimum problem for functional (11) is called a regularized (approximate) solution $P^{\alpha}(U)$ to equation (5) and can be found from the Euler equation for the functional $M_{\alpha}$ :

$$
\alpha\left\{\xi(U) \cdot P(U)-\frac{d}{d U}\left[\chi(U) \cdot \frac{d P(U)}{d U}\right]\right\}+\int_{U_{\min }}^{U_{\max }} \bar{K}(U, t) P(t) d t=g(U),
$$

with boundary conditions

$$
\frac{d P}{d U}\left(U_{\min }\right)=0, \quad \frac{d P}{d U}\left(U_{\max }\right)=0
$$

where $\bar{K}(U, t)=\int_{T_{\min }}^{T_{\max }} K(T, U) \cdot K(T, t) d T$, a $g(U)=\int_{T_{\min }}^{T_{\max }} K(T, U) \cdot Z(T) d T$.

Another difficulty lies in the fact that the right-hand side of (5) in our problem is the result of an experiment, i.e. known on the grid by $T:\left\{T_{1}, \cdots, T_{N}\right\}$. With this right-hand side, equation (5) has no solution at all, understood in the classical sense, i.e. determined by the formula $p=A^{-1} z$ ( $A^{-1}$ is the operator inverse to the operator $A$ ) in equation (5) since the kernel $K^{d, m}(T, U)$ has a continuous derivative with respect to $T$ and, therefore, the right-hand side must also have a continuous derivative with respect to $T$. This means that in this formulation of the problem, the exact solution $\hat{P}(U)$ of this equation with an approximately known right-hand side $Z^{d, m}(T) \neq \hat{Z}^{d, m}(T)$ cannot be taken as an 
approximate to $P(U)$ solution of equation (5), since such a solution may not exist. In this regard, it becomes necessary to pass from the continuous initial problem of finding regularized approximate solutions (5) to its discrete analogue. This transition is carried out by discretizing the boundary value problem for the Euler equation by solving the resulting SLAE [7]. Following the variational approach, we take a discrete analogue of stabilizer (10) and form an analogue of the smoothing functional (11). Then we turn to his Euler equation (13), which will represent the regularized SLAE. The solution to this system (with an appropriately selected regularization parameter) will be an approximate solution to the original problem.

For simplicity of further consideration, we will accept $\xi(U) \equiv \xi$ and $\chi(U) \equiv \chi \quad(\xi$ and $\chi$ are positive numbers). Then the difference analogue of Eq. (13) on a uniform grid of $N$ nodes by $U$ in increments of $\Delta U=\frac{U_{\max }-U_{\min }}{N-1}$ will have the following form:

$$
\sum_{j=2}^{N-1} \bar{K}_{i j} \cdot P_{j} \cdot \Delta U+\frac{\bar{K}_{i 1} \cdot P_{1}+\bar{K}_{i N} \cdot P_{N}}{2} \Delta U+\alpha \xi \cdot P_{i}+a \chi \frac{2 P_{i}-P_{i-1}-P_{i+1}}{(\Delta U)^{2}}=g_{i}, i=1, \cdots, N,
$$

where $U_{i}=U_{\min }+(i-1) \cdot \Delta U, P_{i}=P\left(U_{i}\right), g_{i}=g\left(U_{i}\right), \bar{K}_{i j}=\bar{K}\left(U_{i}, T_{j}\right)$. In this expression the integral is replaced by the corresponding integral sum by the trapezoidal formula, and $\frac{d^{2} P(U)}{d U^{2}}$ by the corresponding difference relation. For simplicity, we will assume that the number of grid nodes by $T$ is also $N$, and the step $\Delta T=\frac{T_{\max }-T_{\min }}{N-1}$. Then $T_{j}=T_{\min }+(j-1) \cdot \Delta T$ and the values $\bar{K}_{i j}$ and $g_{i}$ can also be calculated using the trapezoidal formula:

$$
\bar{K}_{i j}=\sum_{m=2}^{N-1} K_{m i} \cdot K_{m j} \cdot \Delta T+\frac{K_{1 i} \cdot K_{1 j}+K_{N i} \cdot K_{N j}}{2} \Delta T \text { and } g_{i}=\sum_{j=2}^{N-1} K_{j i} \cdot Z_{j} \cdot \Delta T+\frac{K_{1 i} \cdot Z_{1}+K_{N i} \cdot Z_{N}}{2},
$$

where $Z_{j}=Z\left(T_{j}\right)$ and $K_{j i}=K\left(T_{j}, U_{i}\right)$.

For $i=1$ and $i=N,(15)$ contains unknown values of $P_{0}$ and $P_{N+1}$. To satisfy the boundary conditions (14), we put $P_{0}=P_{1}$ and $P_{N+1}=P_{N}$.

System (15) can be written in matrix form with respect to the vector $P=\left(P_{1}, \cdots P_{N}\right)$ :

$$
B \cdot P+\alpha C \cdot P=g,
$$

where the vector $g=\left(g_{1}, \cdots, g_{N}\right)$, the matrix $B$ has the form:

$$
B=\left[\begin{array}{ccccc}
\frac{\bar{K}_{11}}{2} \Delta U & \bar{K}_{12} \Delta U & \cdots & \bar{K}_{1 N-1} \Delta U & \frac{\bar{K}_{1 N}}{2} \Delta U \\
\vdots & \vdots & & \vdots & \vdots \\
\frac{\bar{K}_{N 1}}{2} \Delta U & \bar{K}_{N 2} \Delta U & \cdots & \bar{K}_{N N-1} \Delta U & \frac{\bar{K}_{N N}}{2} \Delta U
\end{array}\right],
$$

and $\alpha C$ is a symmetric matrix of the form:

$$
\left[\begin{array}{cccccc}
\alpha\left(\xi+\frac{\chi}{(\Delta U)^{2}}\right) & -\frac{\alpha \chi}{(\Delta U)^{2}} & 0 & 0 & \cdots & 0 \\
-\frac{\alpha \chi}{(\Delta U)^{2}} & \alpha\left(\xi+\frac{2 \chi}{(\Delta U)^{2}}\right) & -\frac{\alpha \chi}{(\Delta U)^{2}} & 0 & \ldots & 0 \\
0 & -\frac{\alpha \chi}{(\Delta U)^{2}} & \alpha\left(\xi+\frac{2 \chi}{(\Delta U)^{2}}\right) & -\frac{\alpha \chi}{(\Delta U)^{2}} & \cdots & 0 \\
- & \bullet & \bullet & & \\
0 & \cdots & 0 & -\frac{\alpha \chi}{(\Delta U)^{2}} & \alpha\left(\xi+\frac{\chi}{(\Delta U)^{2}}\right)
\end{array}\right]
$$


In our case, boundary conditions (14) can be supplemented by conditions of the form: $P\left(U_{\min }\right)=P\left(U_{\max }\right)=0$, in this case, the matrix $\alpha C$ will have the form:

$$
\left[\begin{array}{cccccc}
0 & -\frac{\alpha \chi}{(\Delta U)^{2}} & 0 & 0 & \ldots & 0 \\
0 & \alpha\left(\xi+\frac{2 \chi}{(\Delta U)^{2}}\right) & -\frac{\alpha \chi}{(\Delta U)^{2}} & 0 & \ldots & 0 \\
0 & -\frac{\alpha \chi}{(\Delta U)^{2}} & \alpha\left(\xi+\frac{2 \chi}{(\Delta U)^{2}}\right) & -\frac{\alpha \chi}{(\Delta U)^{2}} & \ldots & 0 \\
& \bullet & \bullet & \bullet & & \\
0 & \ldots & 0 & 0 & -\frac{\alpha \chi}{(\Delta U)^{2}} & 0
\end{array}\right] .
$$

Thus, the problem is reduced to solving the SLAE with respect to the vector $P=\left(P_{1}, \cdots P_{N}\right)$.

\section{DISCUSSION OF THE RESULTS}

The spectral function $P^{T}(U)$ found by the Tikhonov regularization method has a maximum in the region of $0.04 \mathrm{eV}$ corresponding to the $\alpha$-peak of acoustic absorption and largely coincides with the quasi-Gaussian function $P^{G}(U)$ empirically selected in [3] (Fig. 2).

In this case, the position of the maximum of the $P^{T}(U)$ depends on the structural state of the sample. This fact numerically and qualitatively correlates with the conclusions of [3] about the change in the effective value of the activation energy $U_{e f f}=\int_{0}^{\infty} U P(U) d U \cong U_{0}+\frac{D^{2}}{U_{0}}$ due to the change in the statistical scatter characterized by the dispersion parameter $D$ (Table).

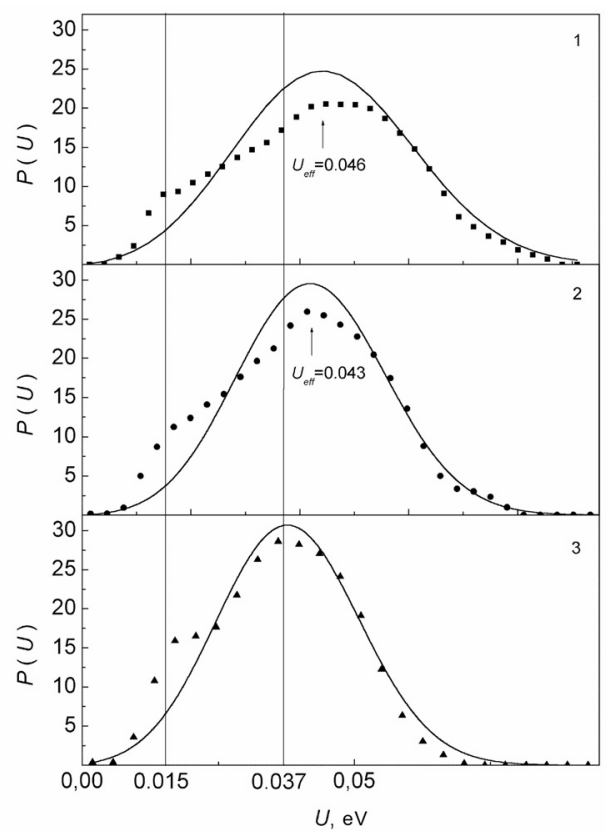

Figure 2. Spectral functions (distribution functions of activation energy values) $P^{G}(U)$ and $P^{T}(U)$ for various structural states of the sample (the numbering of structural states corresponds to that shown in Fig. 1):

-, $\bullet, \boldsymbol{\Delta}$ - the spectral function $P^{T}(U)$ which was found by the Tikhonov regularization method; solid lines - spectral function $P^{G}(U)$ calculated by formula (4) for the quasi-Gaussian distribution function with an appropriate choice of values $U_{0}$ and $D$

The spectral function $P^{T}(U)$ also has a feature in the form of a second mode in the region of $0.015 \mathrm{eV}$; the position of this feature is practically independent of the structural state of the sample. If we assume that this feature corresponds to a relaxation resonance ( $\alpha^{\prime}$-peak) with the same value of $\tau_{0}$ as the main resonance, then it should correspond to a feature in the form of a peak on temperature dependence of the $\delta$ and a step on temperature dependence of the $\Delta M / M_{0}$ in the region of $14-16 \mathrm{~K}$ (at an oscillation frequency sample $88 \mathrm{kHz}$ ). In [3] these features were not found experimentally, which may be associated with a significant broadening of the main relaxation resonance at a temperature of $\approx 54 \mathrm{~K}$. However, in one form or another, the $\alpha^{\prime}$-peak was repeatedly observed by various 
authors [8]-[19]. For example, in [10] a resonance in the region of $17 \mathrm{~K}$ was found in Fe single crystal with an orientation $<100>$. It was shown in [16] that annealing leads to a narrowing and a shift toward lower temperatures of the $\alpha$-peak and the appearance of a $\alpha^{\prime}$-peak that was not observed in the initial curves. It was shown in [17], [18] that the $\alpha^{\prime}$-peak should be characterized by the same period of attempts as the $\alpha$-peak and have a value of the order of $10^{-11} \mathrm{~s}$.

Table. Acoustic relaxation parameters in a single-crystal sample of high-purity iron with orientation $<731>$ in various structural states, according to the data of [3], [4]:

\begin{tabular}{|c|c|c|c|}
\hline \multirow{2}{*}{$\begin{array}{c}\text { Relaxation } \\
\text { parameters }\end{array}$} & \multicolumn{3}{|c|}{ Structural state of the sample } \\
\cline { 2 - 4 } & $\mathbf{1}$ & $\mathbf{2}$ & $\mathbf{3}$ \\
\hline$U_{0}^{\alpha}, \mathrm{eV}$ & 0.0177 & 0.037 & 0.0143 \\
\hline$D^{\alpha}, \mathrm{eV}$ & 0.00472 & 0.00271 & 0.00180 \\
\hline$C_{r} \Delta_{0}$ & 0.046 & 0.043 & 0.042 \\
\hline$U_{e f f}^{\alpha}, \mathrm{eV}$ & \multicolumn{3}{|}{} \\
\hline$\tau_{0}^{\alpha} \cdot 10^{11}, \mathrm{~s}$ & \multicolumn{3}{|}{} \\
\hline$U_{0}^{\alpha^{\prime}}, \mathrm{eV}$ & \multicolumn{3}{|c|}{0.015} \\
\hline
\end{tabular}

In order to detect the $\alpha^{\prime}$-peak in Fe single crystals of the $<731>$ orientation, additional experimental studies were carried out in [4]. A sample in the form of a thin plate was made from the same single crystal as in [3]. The acoustic properties of this sample were studied in the temperature range 4.5-150 K. It was found that in the undeformed sample $\alpha$ and $\alpha^{\prime}$ peaks are not observed, deformation leads to the appearance of $\alpha$-peak localized at $35 \mathrm{~K}$ and its $\alpha^{\prime}$ satellite at a temperature of $13 \mathrm{~K}$. Subsequent annealing at $320 \mathrm{~K}$ leads to a decrease in the height of the $\alpha$ peak, narrowing and shifting to lower temperatures, while the $\alpha^{\prime}$-peak becomes more pronounced. The analysis performed in [4] made it possible to establish the microscopic nature of the $\alpha^{\prime}$-peak and determine the corresponding activation energy of an elementary relaxator $U_{0}^{\alpha^{\prime}}=0.015 \mathrm{eV}$; it was also shown that the activation energy values corresponding to the $\alpha^{\prime}$-peak have a small statistical spread, which practically does not change with a change in the structural state sample.

Thus, the values of the activation energy $U_{0}^{\alpha}=0.037 \mathrm{eV}$ and $U_{0}^{\alpha^{\prime}}=0.015 \mathrm{eV}$ determined experimentally in [4] corresponding to the $\alpha$-peak and its $\alpha^{\prime}$ satellite are in good agreement (taking into account the statistical spread) with the positions of the peaks on the dependence $P^{T}(U)$ obtained by solving the inverse problem, and its substitution into expression (3) makes it possible to exhaustively describe the experimentally observed spectrum of low-temperature acoustic relaxation in iron (Fig. 1).

\section{CONCLUSIONS}

A mathematical procedure for processing experimental data is proposed that allows solving the inverse problem of low-temperature mechanical spectroscopy - to restore the energy spectrum of relaxation by analyzing the temperature dependence of acoustic absorption.

(D) Yuri A. Semerenko, https://orcid.org/0000-0003-2268-0572

\section{ORCID IDs}

\section{REFERENCES}

[1] A.S. Nowick, and B.S. Berry, Anelastic relaxation in crystalline solids, (Academic Press, New York and London, 1972).

[2] V.D. Natsik, and Yu.A. Semerenko, Low Temp. Phys. 42, 138 (2016), https://doi.org/10.1063/1.4942907.

[3] V.D. Natsik, P.P. Pal-Val, L.N. Pal-Val, and Y.A. Semerenko, Low Temperature Physics, 26, 522 (2000); https://doi.org/10.1063/1.1306411.

[4] V.D. Natsik, and Yu.A. Semerenko, Low Temp. Phys. 45, 551 (2019), https://doi.org/10.1063/1.5097366.

[5] H.F. Guliyev, and V.N. Nasibzadeh, Vestnik Tomskogo gosudarstvennogo universiteta. Matematica i mekhanika [Tomsk State University Journal of Mathematics and Mechanics], 54, 5 (2018), https://doi.org/10.17223/19988621/54/1.

[6] O.V. Mozgovy, Технологические системы [Technological Systems Journal], 3(68), 50 (2014), http://www.technologicalsystems.com.ua/images/journal/2014/files/ts68.pdf. (in Russian)

[7] A.N. Tikhonov, and V.Ya. Arsenin, Solutions of Ill-Posed Problems, (Halsted Press, 1977).

[8] M. Kakegawa, and K. Sakamoto, Jpn. J. Appl. Phys. 9, 1057 (1970), https://doi.org/10.1143/JJAP.9.1057.

[9] K. Takita, and K. Sakamoto, Scripta Metall. 4, 403 (1970), https://doi.org/10.1016/0036-9748(70)90110-9.

[10] P.P. Pal-Val, V.D. Natsik, and S. Kadečková, Philosophical Magazine A, 56(3), $407 \quad$ (1987), https://doi.org/10.1080/01418618708214396.

[11] I.G. Ritchie, J.F. Dufresne, and P. Moser, Proc. ICIFUAS-6. ed. by R.R. Hasiguti, N. Mikoshiba, (University of Tokyo Press 1977), pp. 701.

[12] L.B. Magalas, and P. Moser, J. de Phys. Colloques, 42, C5-97 (1981), https://doi.org/10.1051/jphyscol:1981514.

[13] P. Astie, J.P. Peyrade, and P. Groh, Proc. ECIFUAS-3, ed. by C.C. Smith, (Pergamon Press, 1980), pp. 49.

[14] P. Astie, J.P. Peyrade, and P. Groh, Scripta Metall. 14, 611 (1980), https://doi.org/10.1016/0036-9748(80)90008-3. 
[15] P. Astie, J.P. Peyrade, and P. Groh, J. de Phys. 42, C5-91 (1981), http://dx.doi.org/10.1051/jphyscol:1981513.

[16] P. Astie, Proc. of Summer School on Internal Friction in Solids, ed. by S. Gorczyca, L.B. Magalas, (Cracow, Poland, 1984), pp. 43.

[17] L.B. Magalas, Thesis, Academy of Mining and Metallurgy, Cracov, 1982.

[18] L.B. Magalas, Proc. of Summer School on Internal Friction in Solids, ed. by S. Gorczyca, L.B. Magalas, (Cracow, Poland, 1984), pp. 89.

[19] Yu.A. Semerenko, Proc. 21 th Int. Conf. "Relaxation Phenomena in Solids", (Voronezh, Russia, 2004), ISBN 5-9273-0617-9, pp. 234.

\section{СПЕКТР ЕНЕРГІЇ АКТИВАЦІЇ НИЗЬКОТЕМПЕРАТУРНОЇ АКУСТИЧНОЇ РЕЛАКСАЦІЇ В МОНОКРИСТАЛІЧНОМУ ЧИСТОМУ ЗАЛІЗІ. ВИРІШЕННЯ ЗВОРОТНОЇ ЗАДАЧІ МЕХАНІЧНОӤ СПЕКТРОСКОПІЇ МЕТОДОМ РЕГУЛЯРИЗАЦІЇ ТИХОНОВА Ю.О. Семеренко}

Інститут фізики та техніки низьких температур імені Б. Вєркіна, НАН Украӥни пр. Науки 47, 61103, Харків, Украӥна

При вивченні температурних залежностей акустичного поглинання та модуля пружності часто спостерігаються релаксаційні резонанси - піки поглинання, яким на температурній залежності модуля пружності відповідає характерна сходинка. Вважається, що виникнення таких релаксаційних резонансів пов'язано з наявністю в структурі матеріалу елементарних мікроскопічних релаксаторів, що взаємодіють 3 досліджуваною коливальною модою механічних коливань зразка. В достатньо досконалому матеріалі такий процес характеризується часом релаксації $\tau$, а у реальному матеріалі з дефектами - спектром часу релаксації $P(\tau)$. Найчастіше такі релаксаційні процеси мають термічно активований характер і час релаксації $\tau(T)$ визначається співвідношенням Ареніуса $\tau(T)=\tau_{0} \exp \left(U_{0} / k T\right)$, а характеристиками процесу будуть $U_{0}$ - енергія активації, $\tau_{0}$ - період спроб, $\Delta_{0}$ - характерний елементарний внесок окремого релаксатора у динамічний відгук матеріалу та їх спектри. В області низьких температур $k T \ll U_{0}$ статистичним розподілом параметрів $\tau_{0}$ та $\Delta_{0}$ з експоненційною точністю можна знехтувати, а релаксаційний внесок у температурні залежності поглинання та динамічного модуля пружності матеріалу будуть визначатися тільки спектром енергій активації $P(U)$ мікроскопічних релаксаторів. Основна задача механічної спектроскопії при аналізі таких релаксаційних резонансів зводиться до визначення $U_{0}, \tau_{0}, \Delta_{0}$ та $P(U)$. У роботі показано, що проблема знаходження спектральної функції $P(U)$ для енергії активації акустичної релаксації в реальних кристалах з дефектами, зводиться до вирішення інтегрального рівняння Фредгольма I роду 3 приблизно відомою правою частиною і відноситься до класу некоректно поставлених задач. Запропоновано метод визначення $P(U)$ виходячи 3 експериментальних температурних залежностей акустичного поглинання чи модуля пружності, що грунтується на алгоритмі тихоновської регуляризації. Встановлено, що акустична релаксація у чистому монокристалічному залізі в області температур $5 \div 100$ К характеризується двомодовою спектральною функцією $P(U) 3$ максимумами в області $0.037 \mathrm{eB}$ та $0.015 \mathrm{eB}$, що відповідають $\alpha$-піку та його $\alpha^{\prime}$ сателіту.

КЛЮЧОВІ СЛОВА: акустична релаксація, регуляризація Тихонова, спектр енергії активації, акустичне поглинання, модуль пружності 